\title{
Kaposi Sarcoma among non-HIV patients with hematological malignancy: An unusual reality
}

\author{
Giamal Edin Gmati ${ }^{*}$, Farhan Khalid ${ }^{2}$, Abdullah Abdulaziz Alharbi ${ }^{3}$, Muhammad Al-Nahdi ${ }^{2}$ and Ahmed Alaskar ${ }^{4}$ \\ ${ }^{1}$ Adult Hematology \& HSCT, Department of Oncology, King Abdulaziz Medical City (KAMC), Riyadh, Saudi Arabia \\ ${ }^{2}$ Adult Hematology, Department of Oncology, King Abdulaziz Medical City (KAMC), Riyadh, Saudi Arabia \\ ${ }^{3}$ Assistant Professor of Haematopathology \& Transfusion Medicine, Co-coordinator of Haematology Block, Basic Medical Sciences Department, College of \\ Medicine, Al Imam Mohammad, Ibn Saud Islamic University (IMSIU) Saudi Arabia \\ ${ }^{4}$ Executive Director, King Abdullah International Medical Research Center (KAIMRC), Associate Professor, Adult Hematology \& HSCT, King Saud Bin \\ Abdulaziz University for Health Sciences (KSAUHS), Riyadh, Saudi Arabia
}

\begin{abstract}
Hematological malignancies are group of heterogeneous diseases with varied incidence, etiology and prognosis. Looking over the leukemia's, Chronic lymphocytic leukemia (CLL) is one of the most frequently diagnosed condition among multiple types of leukemia's while among lymphomas, the non-Hodgkin's lymphomas including follicular lymphoma and diffuse large B-cell lymphoma, comprising $60 \%$ of lymphoma cases. About $25 \%$ ofCLL patients having cutaneous manifestations, which may be of infectious or hemorrhagic origin. Risk of skin cancer among patients with hematological malignancies also increases up to several folds as compared to general population so the cutaneous lesion is considered as the first step towards the secondary skin malignancy.
\end{abstract}

Herein we report fourpatients with hematological malignancies of Kaposi Sarcoma (KS), as a secondary malignant lesion among the diagnosed non-HIV patients of hematological malignancies.We conclude from reporting these 4 cases concluded that theconsulting hematology physician consider diagnosis of in patients with hematological malignancy whether HIV positive or negative.

\section{Introduction}

Hematological malignancies are a group of heterogeneous diseases with varied incidence, etiology and prognosis. The classification proposed by WHO for hematological malignancies are on the basis of lineage that is myeloid neoplasms, lymphoid neoplasms, mast cell disorders, and histiocytic neoplasms [1]. But for the sake of simplicity studies classified hematological malignancies into broad categories including Hodgkin versus non-Hodgkin lymphoma, acute versus chronic leukemia [2-4].

Chronic lymphocytic leukemia (CLL) is one of the most frequently diagnosed condition among multiple types of leukemia's [5]. Pathologically CLL occurs due to the increased number of mature but incompetent B-lymphocytes which are found in peripheral blood, bone marrow and secondary lymphoid organs including spleen and lymph nodes $[6,7]$.

Among non-Hodgkin's lymphomas the most common types are diffuse large B-cell lymphomaand follicular lymphoma, comprising the $60 \%$ of lymphoma cases. Pathologically the tumor involving the B, T or natural killer lymphocytes [8].

Kaposi sarcoma (KS) is a malignant tumor of lymphatic endothelium, frequently affecting the individual having human immunodeficiency (HIV) virus infection but can also affect the HIV-negative immunocompromised individuals [9,10]. Studying the underlying pathology, it's an angioproliferative disorder, caused by human herpes virus 8 (HHV-8) infection, which is also named as KS-associated Herpes virus $\{(\mathrm{KSHV})$ [11-12]\}. On the basis of clinical presentation KS has four types, including classic type which was first diagnosed by Kaposi, the second one is endemic type which is usually found in HIV-negative Africans, the third one is iatrogenic type which is found in immunocompromised individuals like those who are on immunosuppressive treatment, or among individuals with renal allograft and the last but most frequently found type is epidemic among individuals with HIV $\{$ (AIDS, associated $[13,14]\}$.

\section{Case Report}

\section{Case-I}

Seventy-six-year-oldmale,diagnosed withosteoarthritis and Chronic Lymphocytic Leukemia in July 2006 RAI stage 0 which progressed to RAI stage IV, in October 2012. Patient was started on FR protocol (Rituximab $375 \mathrm{mg} / \mathrm{m}^{2}$ and Fludarabine $25 \mathrm{mg} / \mathrm{m}^{2}$ ). $\mathrm{He}$ attended the clinic in December 2012 with Complaints of multiple lumps on the left side of the neck with compression symptoms, shortness of breath especially during sleep, hoarseness of voice, difficulty in swallowing and pain during neck movement. On examination multiple brown nodular plaque found at the back of neck, involving most of the lateral aspect of the neck (Figure 1). The biopsy report confirmed the diagnosis of Kaposi sarcoma (Figure 2). His serology workup which

${ }^{\star}$ Correspondence to: Giamal Edin Gmati MSc. FRCP (Edin), Consultant, Adult Hematology, Department of Oncology, King Abdulaziz Medical City, Ministry of National Guard, P O Box 22490 Riyadh 11426, Saudi Arabia, Tel: +966 11801111 Ext 53385; Fax+966 118011111 Ext 53364; E-mail, gmatiga@ngha.med.sa

Received: September 06, 2018; Accepted: September 19, 2018; Published: September 24,2018 


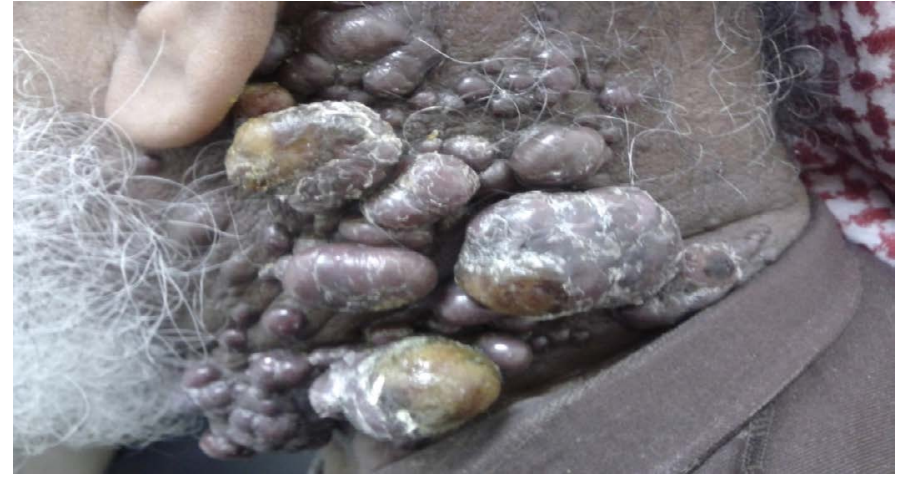

Figure 1. Multiple brown nodular plaque found at the back of neck, involving most of the lateral aspect of the neck

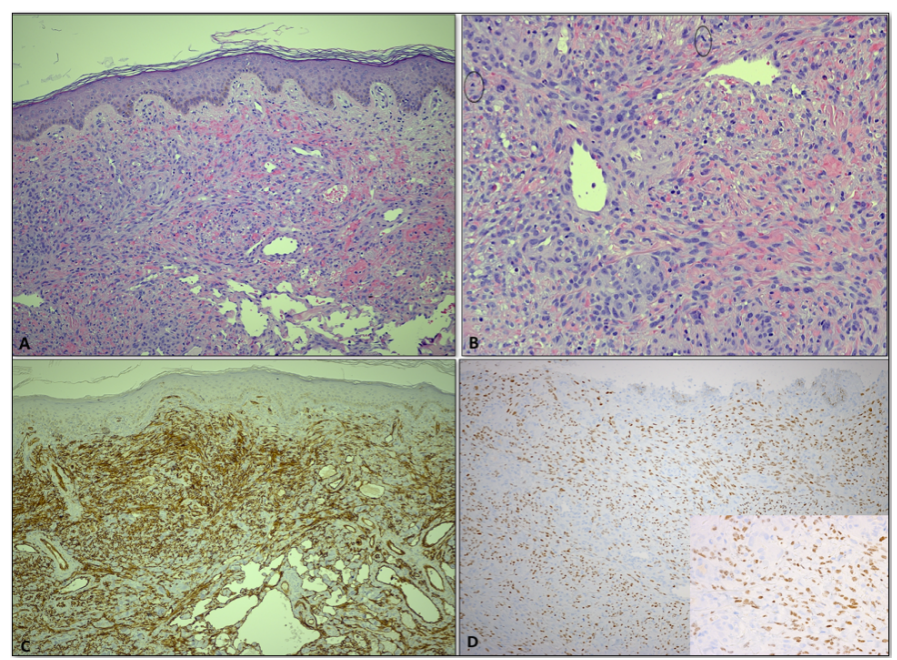

Figure 2. Kaposi sarcoma, A. The dermis expanded by fascicles of monomorphic spindle cells forming slit-like vascular channels containing erythrocytes (H\&E stain, $5 X)$. B.Higher magnification withmoderate mitotic activity (circle) $(H \& E$ stain, $40 X)$. C.CD31 highlights the many dilated vascular spaces (CD31 immunohistochemistry, $5 X)$. D.The nuclei of the tumor cells demonstrate immunoreactivity for HHV-8 ( $5 X, 40 X$ "inset")

included HIV was negative. He was seen by medical oncology and was offered treatment in the form of Docetaxel $30 \mathrm{mg} / \mathrm{m}^{2}$.

\section{Case-II}

Sixty-eight-year-old female, known case of diabetes mellitus and hypertension. She was on workup under Hematology in March 2009 for possible diagnosis of lymphoma. She underwent Bone marrow aspiration and biopsy that was suggestive of B- cell lymphomatous infiltration. Subsequently the diagnosis of low grade B-cell Lymphoma was made however she was lost to follow-up.

In July 2017, she was admitted with chest discomfort, severe dyspnea and productive cough for 10 days along with history of weight loss of $40 \mathrm{Kg}$ within last 4-5 months. She also complained of multiple bilateral skin lesions on calf area which were brownish multiple involving both legs (Figure 3). Her chest X-ray showed pleural effusion. Her CT scan showed paravertebral mass, lymphadenopathies in abdomen and mediastinum. She underwent paravertebral mass biopsy which confirmed Diffuse Large B Cell Lymphoma. Biopsy was done for the skin lesion that confirmed Kaposi sarcoma. She was negative on HIV testing. She was started on treatment for lymphoma and KS treatment was delayed.

\section{Case-III}

Sixty-seven-year-old male presented in emergency room with complain of cough and shortness of breath for 1 week. The past medical history revealed that he was a diagnosed case of Low grade lymphoma since 2002. He received treatment FR Protocol (Rituximab $375 \mathrm{mg} /$ $\mathrm{m} 2$ and Fludarabine $30 \mathrm{mg} / \mathrm{m} 2$ ) total of 6 cycles completed in 2004 . He was in remission until May 2016, when he presented with history cough with expectorated yellow sputum and shortness of breath for 1 week. He also noticed skin lesion over the groin and lower limb area which were multiple asymmetric, brownish which was examined by the physician and biopsy was sent. The biopsy report confirmed the Kaposi sarcoma. Serology including HIV was negative. Patient died of other complications and was not given treatment of KS.

\section{Case- IV}

Seventy-four-year-old male, known case of Diabetes mellitus and hypertension left ventricular diastolic dysfunction and chronic renal failure, and was diagnosed as CLL RAI stage I in 2006. In March 2013 he presented with skin lesions over both legs with edema over the left leg. On examination multiple indurated brownish violaceous plaques over legs were observed (Figure 4). The biopsy report manifested atypical vascular proliferation with extravasated red blood cells consistent with Kaposi sarcoma. Patient received treatment with Docetaxel $30 \mathrm{mg} / \mathrm{m}^{2}$

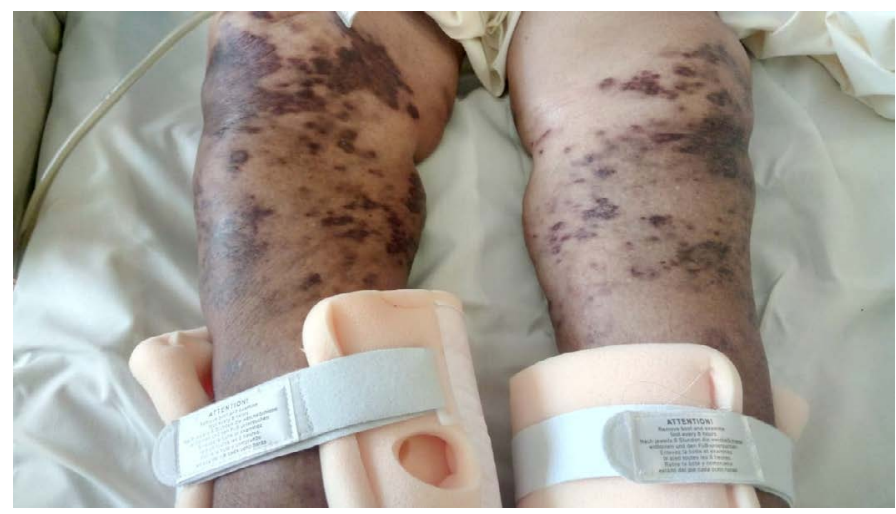

Figure 3. Multiple bilateral skin lesions on calf area which were brownish multiple involving both legs

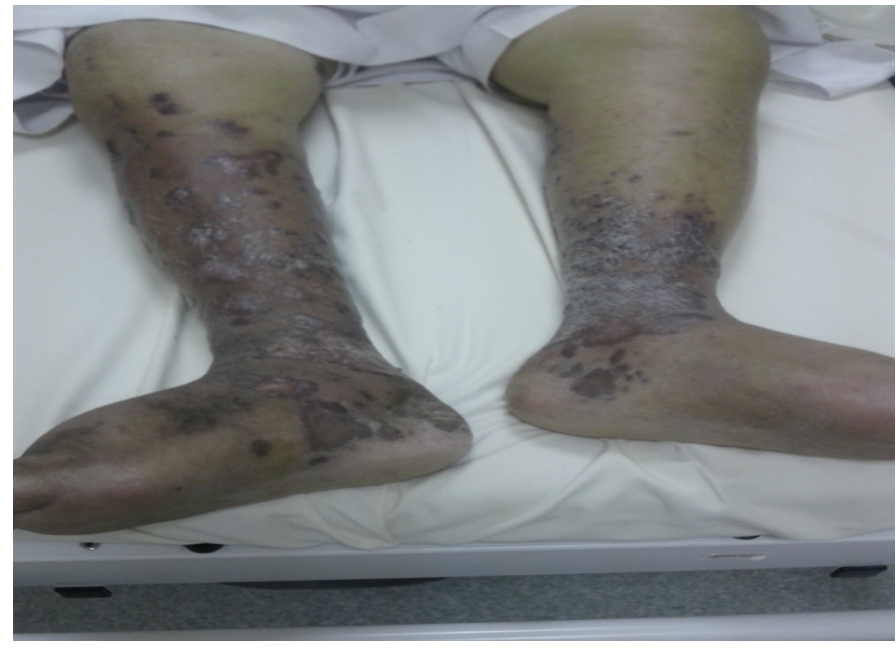

Figure 4. Multiple indurated brownish violaceous plaques over legs 


\section{Discussion}

The Entity of KS was first described by Moritiz Kaposi in 1872. KS has been seen in lymphoproliferative disease, majority of which are HIV patients. KS is usually caused by human herpes virus 8 (HHV8) infection. Pathologically HHV-8 attack over the endothelial cells and convert it into spindle cells [15]. During its proliferative phase, the infected endothelial cells release vascular endothelial growth factor (VEGF). This activation of endothelial cells finally lead to formation of tumor [16]. The patients with hematological malignancies are immunocompromised due to the imbalance in the circulating $\mathrm{T}$ and B-lymphocytes. So the HHV-8 infection and endothelial activation can provoke the KS lesion among these patients [17-18].

Literature review revealed a strong relationship between immune suppressant therapy especially after organ transplant and KS. Since half of our cases reported have CLL, we searched the literature and in fact there is a lack of reports that strongly suggest any association between CLL and KS as very few cases are reported [19-21]. Immunosupression is a significant clinical feature in CLL patient which results from Hypogammaglobinemia and cellular immune dysfunction therefore, patients with CLL will be prone to bacterial, viral and fungal infection. This might be one of the causes of KS in such patients. CLL patients are five times more prone to develop KS when comparing with the general population [20].This was previously reported by F. Kose et.al, in CLL patient [19].Pulmonary involvement among the patients make it more difficult to diagnose KS, as the Arber Kadar, et al. reported [21].

People suffering with HIV are at a higher risk of developing complications such as KS, which is a 50,000 fold higher in HIV as compared to normal population, similarly non-Hodgkin's lymphoma (including Burkett lymphoma (57-fold), diffuse large B-cell lymphoma (98-fold) and central nervous system (CNS) lymphoma (5000-fold) [22]. KS remains the second most frequent tumor arising in HIVinfected patients in the United States and is particularly common in sub-Saharan Africa [23]. Lymphoma cases which were reported to have KS, majority are HIV positive [17,24-26] but in the current report the non-HIV lymphoma patients have developed KS, which is the rare entity.

\section{Conclusion}

Patients with hematological malignancies especially CLL and nonHodgkin lymphoma, are prone to develop KS but the exact mechanism is still unclear, Awareness of the association of KS with hematological malignancy needs to be increased among practicing Heamatologists. Multi-disciplinary team management including a Hematologist, Medical Oncologist and Dermatologist should be encouraged from a standard of care approach.

\section{Reference}

1. Harris NL, Jaffe ES, Diebold J, Flandrin G, Muller-Hermelink HK, et al. (2000) The World Health Organization classification of hematological malignancies report of the clinical advisory committee meeting, Airlie House, Virginia, November 1997. Modern pathology 13: 193 .

2. Curado MP, Edwards B, Shin HR, Storm H, Ferlay J, et al. (2007) Cancer incidence in five continents, Volume IX: IARC Press, International Agency for Research on Cancer.

3. Ferlay J (GLOBOCAN 2002) Cancer incidence, mortality and prevalence worldwide. IARC Cancer Base No. 5

4. Sant M, Allemani C, Tereanu C, De Angelis R, Capocaccia R, et al. (2010) Incidence of hematological malignancies in Europe by morphological subtype: results of the HAEMACARE project. Blood 16: 3724-3734.

5. Byrd JC, Stilgenbauer S, Flinn IW (2004) Chronic lymphocytic leukemia. Hematology Am Soc Hematol Educ Program. [Crossref]
6. Kipps TJ (2007) Chronic lymphocytic leukemia: Elsevier.

7. Jain P, O'Brien S (2015) Chronic lymphocytic leukemia. Targeted therapy in translational cancer research: John Wiley \& Sons, Hoboken, NJ pp. 130-144.

8. Morin RD, Mendez-Lago M, Mungall AJ, Goya R, Mungall KL, et al. (2011) Frequent mutation of histone-modifying genes in non-Hodgkin lymphoma. Nature 476: 298.

9. Hong YK, Foreman K, Shin JW, Hirakawa S, Curry CL, et al. (2004) Lymphatic reprogramming of blood vascular endothelium by Kaposi sarcoma-associated herpesvirus. Nature genetics 36: 683 .

10. Grundhoff A, Ganem D (2004) Inefficient establishment of KSHV latency suggests an additional role for continued lytic replication in Kaposi sarcoma pathogenesis. The Journal of clinical investigation 113: 124-136.

11. Moore PS, Chang Y (2009) Kaposi's sarcoma-associated herpesvirus. Clinical Virology, Third Edition: American Society of Microbiology pp. 537-58.

12. Damania B, Dittmer DP (2008) Kaposi-Sarcoma-Associated Herpesvirus. Human Cancer Viruses 1: 170-185.

13. Schwartz RA, Micali G, Nasca MR, Scuderi L (2008) Kaposi sarcoma: a continuing conundrum. J Am Acad Dermatol 59: 179-206. [Crossref]

14. Krown SE, Singh JC, DeLaney TF, Robinson JK, Pollock RE (2011) Classic Kaposi's sarcoma: clinical features, staging, diagnosis, and treatment. UpToDate Waltham, MA: UpToDate.

15. Wang QJ, Jenkins FJ, Jacobson LP, Kingsley LA, Day RD, et al. (2001) Primary human herpesvirus 8 infection generates a broadly specific $\mathrm{CD} 8(+)$ T-cell response to viral lytic cycle proteins. Blood 97: 2366-2373. [Crossref]

16. Gutierrez-dalmau A, Campistol JM, Sanchez-fructuoso A, Sanz-guajardo A, Mazuecos A, et al. (2004) Conversion to Sirolimus, A Successful Treatment For Posttransplantation Kaposi's Sarcoma. American Journal of Transplantation Supplement 4: 523.

17. Eltom MA, Jemal A, Mbulaiteye SM, Devesa SS, Biggar RJ (2002) Trends in Kaposi's sarcoma and non-Hodgkin's lymphoma incidence in the United States from 1973 through 1998. J Natl Cancer Inst 94: 1204-1210.

18. Andrews JR, Cho-Park YA, Ferry J, Abramson JS, Robbins GK (2011) Kaposi's sarcoma-associated herpesvirus-related solid lymphoma involving the heart and brain. AIDS research and treatment.

19. Kose F, Kocer N, Sumbul A, Sezer A, Yilkan O (2012) Kaposi's sarcoma following chronic lymphocytic leukemia: a rare entity. Case reports in oncology 5: 271-274.

20. Hisada M, Biggar RJ, Greene MH, Fraumeni JF Jr, Travis LB (2001) Solid tumors after chronic lymphocytic leukemia. Blood 98: 1979-1981. [Crossref]

21. Kodra A, Walczyszyn M, GrossmanA C, Zapata D, Rambhatla T, et al. (2015) Case Report: Pulmonary Kaposi Sarcoma in a non-HIV patient. F1000Res 4: 1013. [Crossref]

22. Engels EA, Pfeiffer RM, Goedert JJ, Virgo P, McNeel TS, et al. (2006) Trends in cancer risk among people with AIDS in the United States 1980-2002. AIDS 20: 16451654. [Crossref]

23. Gonçalves PH, Uldrick TS, Yarchoan R (2017) HIV-associated Kaposi sarcoma and related diseases. AIDS 31: 1903-1916. [Crossref]

24. Ledergerber B, Telenti A, Egger M (1999) Risk of HIV related Kaposi's sarcoma and non-Hodgkin's lymphoma with potent antiretroviral therapy: prospective cohort study. Bmj 319: 23-24

25. Oksenhendler E, Boulanger E, Galicier L, Du M-Q, Dupin N, et al. (2002) High incidence of Kaposi sarcoma-associated herpesvirus-related non-Hodgkin lymphoma in patients with HIV infection and multicentric Castleman disease. Blood 99: 23312336.

26. Shiels MS, Pfeiffer RM, Hall HI, Li J, Goedert JJ, et al. (2011) Proportions of Kaposi sarcoma, selected non-Hodgkin lymphomas, and cervical cancer in the United States occurring in persons with AIDS, 1980-2007. JAMA 305: 1450-1459. [Crossref]

Copyright: (C2018 Gmati GM. This is an open-access article distributed under the terms of the Creative Commons Attribution License, which permits unrestricted use, distribution, and reproduction in any medium, provided the original author and source are credited. 